\title{
Alpha-interferon does not increase the efficacy of 5-fluorouracil in advanced colorectal cancer
}

\author{
Meta-Analysis Group in Cancer
}

\begin{abstract}
Summary Two meta-analyses were conducted to quantify the benefit of combining $\alpha$-IFN to $5 F U$ in advanced colorectal cancer in terms of tumour response and survival. Analyses were based on a total of 3254 individual patient data provided by principal investigators of each trial. The meta-analysis of 5FU \pm LV vs. $5 F U \pm L V+\alpha$-IFN combined 12 trials and 1766 patients. The meta-analysis failed to show any statistically significant difference between the two treatment groups in terms of tumour response or survival. Overall tumour response rates were $25 \%$ for patients receiving no $\alpha$-IFN vs. $24 \%$ for patients receiving $\alpha$-IFN (relative risk, RR $=1.02$ ), and median survivals were 11.4 months for patients receiving no $\alpha$-IFN vs. 11.5 months for patients receiving $\alpha$-IFN (hazard ratio, HR $=0.95$ ). The meta-analysis of $5 F U+L V$ vs. $5 F U+\alpha-I F N$ combined 7 trials, and 1488 patients. This meta-analysis showed an advantage for 5FU + LV over $5 F U+\alpha-I F N$ which was statistically significant in terms of tumour response $(23 \%$ vs. $18 \%$; RR $=1.26 ; P=0.042)$, and of a borderline significance for overall survival $(\mathrm{HR}=1.11$; $P=0.066$ ). Metastases confined to the liver and primary rectal tumours were independent favourable prognostic factors for tumour response, whereas good performance status, metastases confined to the liver or confined to the lung, and primary tumour in the rectum were independent favourable prognostic factors for survival. We conclude that $\alpha$-IFN does not increase the efficacy of 5FU or of 5FU + LV, and that $5 \mathrm{FU}+\alpha-\mathrm{IFN}$ is significantly inferior to $5 \mathrm{FU}+\mathrm{LV}$, for patients with advanced colorectal cancer. (C) 2001 Cancer Research Campaign http://www.bjcancer.com
\end{abstract}

Keywords: 5-fluorouracil; interferon; colorectal cancer; meta-analysis

The outcome of patients with non-operable metastatic colorectal cancer remains poor. Four meta-analyses previously performed by the Meta-Analysis Group In Cancer confirmed that the effect of intravenous bolus 5-fluorouracil (5FU) can be increased by the modulation of $5 \mathrm{FU}$ by leucovorin (Advanced Colorectal Cancer Meta-analysis Project 1992) or by methotrexate (Advanced Colorectal Cancer Meta-analysis Project 1994), the administration of 5FU by continuous infusion (Meta-Analysis Group in Cancer 1998), or the administration of fluoropyrimidines through the hepatic artery (Meta-Analysis Group in Cancer 1996) in case of metastases confined to the liver. Each meta-analysis showed a large increase in tumour response, without substantial impact on survival.

In the late $1980 \mathrm{~s}$, alpha-interferon $(\alpha$-IFN) was proposed to increase the efficacy of $5 \mathrm{FU}$ in advanced colorectal cancer. After the initial report by Wadler et al (1989) of a tumour response rate of $76 \%$ in a group of 17 previously untreated patients, additional phase II trials of 5FU plus $\alpha$-IFN with or without leucovorin were undertaken (Pazdur et al, 1990); (Piedbois et al, 1991); (Weh et al, 1992); (Raderer and Scheithauer, 1995) followed by several randomized phase III trials. Most randomized trials were disappointing, but despite a total of 3500 patients enrolled in these studies, there is to date no overall assessment of the true impact of $\alpha$-IFN in advanced colorectal cancer. We therefore decided to

\section{Received 12 July 2000}

Revised 30 October 2000

Accepted 21 November 2000

Correspondence to: Pascal Piedbois, MD, Department of Medical Oncology, Henri Mondor Hospital, Assistance Publique Hôpitaux de Paris, 94000 Creteil, France (Tel. 331498125 82; Fax. 331498125 69;

E-mail:pascal.piedbois@ @mn.ap-hop-paris.fr) explore this question through a meta-analytic approach based on individual patient data. Toxicity was not studied, since at the time of beginning the present analyses, individual trials had already demonstrated that the addition of $\alpha$-IFN to a $5 F U$ regimen led to an increased risk of toxicity.

Writing Committee

Pierre Thirion, Pascal Piedbois, Marc Buyse, Peter J. O'Dwyer, David Cunningham, Anthony Man, Frank A. Greco, Giuseppe Colucci, Claus-Henning Köhne, Francesco Di Costanzo, Andrea Piga, Sergio Palmeri, Patrick Dufour, Allessandra Cassano, Gabor Pajkos, Raul Pensel, N. Faruk Aykan, John Marsh, Matthew T. Seymour

Collaborators: Peter J. O’Dwyer, Louise Ryan, Judith Manola (Eastern Cooperative Oncology Group, Cancer and Leukemia Group B, USA), David Cunningham, Andy Norman (The Royal Marsden Hospital, Sutton, United Kingdom), Matthew T. Seymour, Richard J. Stephens, (Medical Research Council, United Kingdom), Giuseppe Colucci (Gruppo Oncologico dell' Italia Meridionale, Italy), ClausHenning Köhne, Hans-Joachim Schmoll, (Arbeitsgemeinschaft Internische Onkologie, Germany), Francesco Di Costanzo (Gruppo Oncologico Italiano di Ricerca Clinica, Italy), Andrea Piga (University of Ancona, Italy), Sergio Palmeri, (University of Palermo, Italy), Patrick Dufour (Hôpital de Hautepierre, Strasbourg, France), Allessandra Cassano, Carlo Barone, (Universita Catolica S. Cuore, Roma, Italy), Anthony Man (Novartis Pharma, Basel, Switzerland), Frank A. Greco (Sarah Cannon Cancer Center, Nashville, TN, USA), Lawrence Einhorn, (Indiana University Cancer Center, Indianapolis, USA), Gabor Pajkos (MI Central Hospital, Budapest, Hungary), Gyorgy Bodoky (National Institute of Oncology, Budapest, Hungry), Raul Pensel (Hospital Municipal Jose M. Penna, Buenos Aires, Argentina), N. Faruk Aykan, (Istanbul University, Turkey, John Marsh (Yale University School of Medicine, New Haven, CT, USA), Peter Sorensen (Aarhus University Hospital, Aarhus, Denmark), Paris Kosmidis (Helenic Cooperative Oncology Group, Greece), Francesco Recchia (Istituto Oncologico Regione Abruzzo e Molise, Italy), Pierre Thirion (St. Luke's Hospital, Dublin, Ireland), Youri Piedbois, Eric Gauthier, AnneChantal Braud, Alain Piolot (European Association for Research In Oncology, Creteil, France), Pascal Piedbois (Henri Mondor Hospital, Assistance Publique de Paris, Creteil, France), Marc Buyse, Emmanuel Quinaux (International Drug Development Institute, Brussels, Belgium)

Board of the Meta-Analysis Group In Cancer: Norman Wolmark (Pittsburgh, PA, USA) (President), Pascal Piedbois, MD (Creteil, France) (Secretary), Marc Buyse, $\mathrm{ScD}$ (Brussels, Belgium) (Statistician), Charles Erlichman, MD (Rochester, MN, USA), Robert Carlson, MD (Stanford, CA, USA), Youssef Rustum, PhD (Buffalo, NY, USA). 


\section{METHODS}

\section{Trial selection}

Two meta-analyses were conducted concomitantly. In the first one we considered all properly randomised trials comparing 5FU with or without folinic acid $(5 \mathrm{FU} \pm \mathrm{LV})$ to the same $5 \mathrm{FU} \pm \mathrm{LV}$ regimen plus $\alpha$-IFN (5FU \pm LV $+\alpha$-IFN). In the second meta-analysis we considered all properly randomised trials comparing $5 \mathrm{FU}+\mathrm{LV}$ to 5 FU $+\alpha$-IFN. In both meta-analyses, $\alpha$-IFN must have consisted of $\alpha$-2a-interferon or $\alpha$-2b-interferon, and patients must have been included in the trial before July 1996. The search for relevant trials was initiated in October 1996 by consulting MEDLINE, Physician Data Query (PDQ), the proceedings of major conferences since 1989 , and through contacts with principal investigators. A total of 20 relevant trials were identified, but 3 of them (335 patients) could not be included in the meta-analysis, due to lack of data or information on the trial (Kreuser et al, 1995); (Kosmidis et al, 1996); (Recchia et al, 1996).

\section{Meta-analysis of $5 F U \pm L V$ vs. $5 F U \pm L V+\alpha-I F N$ (Table 1 )}

The comparison of $5 F U$ versus $5 F U+\alpha$-IFN was addressed in 7 trials, the Roche International Clinical Research Center (RICRC) trial (Greco et al, 1996), the Palermo trial (Palmeri et al, 1998), the Ancona trial (Piga et al, 1996), two Royal Marsden Hospital $(\mathrm{RMH})$ trials (Hill et al, 1995a+b), the trial from France (Dufour et al, 1996), and the Eastern Cooperative Oncology Group, Cancer and Leukemia Group B (ECOG/CALGB) trial (O'Dwyer et al, 1996). The ECOG/CALGB trial (O'Dwyer et al, 1996) was not considered in the first meta-analysis, because unlike the other trials, the planned dose of 5FU and its mode of administration were not the same in the 2 treatment groups. In most trials, the $5 \mathrm{FU}$ regimen was close to the Wadler regimen (Wadler et al, 1989), consisting of an initial 5-day 5FU infusion followed by a weekly $5 \mathrm{FU}$ infusion. The dose of $5 \mathrm{FU}$ varied from 500 to 750 $\mathrm{mg} / \mathrm{m}^{2} /$ day. The dose of $\alpha$-IFN varied from 3 to $10 \mathrm{MU}, 3$ times a week. Based on the impact of the mode of 5FU administration on tumour response and survival (Meta-Analysis Group In Cancer,

Table 1 Randomised clinical trials comparing $5 F U \pm L V$ to $5 F U \pm L V+\alpha-I F N$ in advanced colorectal cancer

\begin{tabular}{|c|c|c|}
\hline Comparison & Patients & Treatment arms \\
\hline \multicolumn{3}{|c|}{$5 F U$ vs. $5 F U+\alpha-I F N$, with $5 F U$ bolus } \\
\hline $\begin{array}{l}\text { RICRC } \\
\text { Greco et al, } 1996\end{array}$ & 245 & $\begin{array}{l}5 F U 750 \mathrm{mg} / \mathrm{m}^{2} / \mathrm{d} \text { continuous infusion } \mathrm{d} 1 \text { to } \mathrm{d} 5 \text {, then weekly on bolus } \\
\text { Same }+\alpha \text {-IFN } 9 \mathrm{MU} \text { three times a week }\end{array}$ \\
\hline $\begin{array}{l}\text { Palermo } \\
\text { Palmeri et al, } 1998\end{array}$ & 169 & $\begin{array}{l}5 \mathrm{FU} 750 \mathrm{mg} / \mathrm{m}^{2} / \mathrm{d} \text { bolus } \mathrm{d} 1 \text { to } \mathrm{d} 5 \text {; then weekly } \\
\text { Same }+\alpha \text {-IFN } 9 \mathrm{MU} \text { three times a week }\end{array}$ \\
\hline $\begin{array}{l}\text { Ancona } \\
\text { Piga et al, } 1996\end{array}$ & 141 & $\begin{array}{l}5 \text { FU } 500 \mathrm{mg} / \mathrm{m}^{2} / \mathrm{d} \text { bolus } \mathrm{d} 1 \text { to } \mathrm{d} 5 \text {; then weekly } \\
\text { Same }+\alpha \text {-IFN } 3 \mathrm{MU} / \mathrm{d}\end{array}$ \\
\hline $\begin{array}{l}\text { RMH } \\
\text { Hill et al, 1995a }\end{array}$ & 106 & $\begin{array}{l}5 \mathrm{FU} 750 \mathrm{mg} / \mathrm{m}^{2} / \mathrm{d} \text { continuous infusion } \mathrm{d} 1 \mathrm{to} \mathrm{d} 5 \text {; then weekly on bolus } \\
\text { Same }+\alpha-\mathrm{IFN} 10 \mathrm{MU} \text { three times a week }\end{array}$ \\
\hline $\begin{array}{l}\text { France } \\
\text { Dufour et al, } 1996\end{array}$ & 106 & $\begin{array}{l}5 \mathrm{FU} 750 \mathrm{mg} / \mathrm{m}^{2} / \mathrm{d} \text { continuous infusion } \mathrm{d} 1 \text { to } \mathrm{d} 5 \text {; then weekly on bolus } \\
\text { Same }+\alpha \text {-IFN } 9 \mathrm{MU} \text { three times a week }\end{array}$ \\
\hline
\end{tabular}

Comparison $\quad$ Patients $\quad$ Treatment arms

5FU vs. $5 F U+\alpha-I F N$, with $5 F U$ continuous infusion

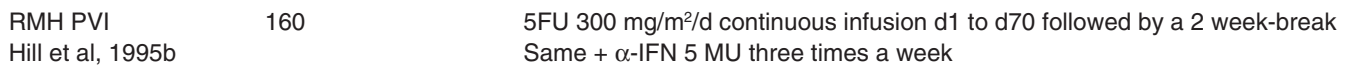

\begin{tabular}{|c|c|c|}
\hline Comparison & Patients & Treatment arms \\
\hline \multicolumn{3}{|c|}{$5 F U+$ LV vs. $5 F U+L V+\alpha-I F N$, with $5 F U$ bolus } \\
\hline $\begin{array}{l}\text { GOIM } \\
\text { Colucci et al, } 1999\end{array}$ & 204 & $\begin{array}{l}\text { 5FU } 375 \mathrm{mg} / \mathrm{m}^{2} / \mathrm{d} \text { bolus } \mathrm{d} 1 \text { to } \mathrm{d} 5,+ \text { I-folinic acid } 100 \mathrm{mg} / \mathrm{m}^{2} / \mathrm{d} \text { bolus } \mathrm{d} 1 \text { to } \mathrm{d} 5 \text { every } 3 \text { weeks } \\
\text { Same }+\alpha-\text { IFN } 3 \mathrm{MU} / \mathrm{d} \mathrm{d}-2 \text { to d5 }\end{array}$ \\
\hline $\begin{array}{l}\text { Roma } \\
\text { Cassano et al, } 1996\end{array}$ & 148 & $\begin{array}{l}\text { 5FU } 370 \mathrm{mg} / \mathrm{m}^{2} / \mathrm{d} \text { bolus d } 1 \text { to } \mathrm{d} 5,+ \text { I-folinic acid } 80 \mathrm{mg} / \mathrm{m}^{2} / \mathrm{d} \text { bolus d } 1 \text { to } \mathrm{d} 5 \text { every } 4 \text { weeks } \\
\text { Same }+\alpha \text {-IFN } 3 \mathrm{MU} 3 \text { times a week }\end{array}$ \\
\hline $\begin{array}{l}\text { Hungary } \\
\text { Pajkos et al, } 1997\end{array}$ & 73 & $\begin{array}{l}\text { 5FU } 425 \mathrm{mg} / \mathrm{m}^{2} / \mathrm{d} \text { bolus } \mathrm{d} 1 \text { to } \mathrm{d} 5 \mathrm{LV} 20 \mathrm{mg} / \mathrm{m}^{2} / \mathrm{d} \text { d1 to } \mathrm{d} 5 \text { every } 4 \text { weeks } \\
\text { Same }+\alpha \text {-IFN } 3 \mathrm{MU} \text { three times a week }\end{array}$ \\
\hline $\begin{array}{l}\text { Argentina } \\
\text { Pensel et al, } 1993\end{array}$ & 55 & $\begin{array}{l}\text { 5FU } 600 \mathrm{mg} / \mathrm{m}^{2} / \mathrm{d} \text { bolus } \mathrm{d} 1 \text { to } \mathrm{d} 5+\mathrm{LV} 500 \mathrm{mg} / \mathrm{m}^{2} / \mathrm{d} \text { bolus } \mathrm{d} 1 \text { to } \mathrm{d} 5 \text { every } 3 \text { weeks } \\
\text { Same }+\alpha-\text { IFN } 5 \mathrm{MU} / \mathrm{d}, \mathrm{d} 1 \text { to } \mathrm{d} 5 \text { every } 3 \text { weeks }\end{array}$ \\
\hline Comparison & Patients & Treatment arms \\
\hline \multicolumn{3}{|c|}{$5 F U+$ LV vs. $5 F U+L V+\alpha-I F N$, with $5 F U$ continuous infusion } \\
\hline $\begin{array}{l}\text { MRC } \\
\text { Seymour et al, } 1996\end{array}$ & 260 & 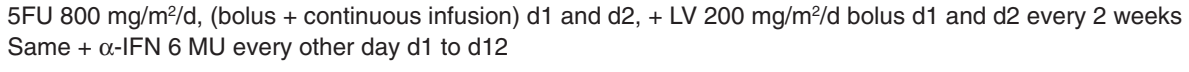 \\
\hline $\begin{array}{l}\text { AlO } \\
\text { Köhne et al, } 1998\end{array}$ & 99 & $\begin{array}{l}5 F U=2600 \mathrm{mg} / \mathrm{m}^{2} / \mathrm{d} \mathrm{IVC}+\mathrm{LV}=500 \mathrm{mg} / \mathrm{m}^{2} / \mathrm{d} \text { bolus, every week } \\
\text { same }+\mathrm{IFN}=3 \mathrm{MIU} / \mathrm{d}, 3 \mathrm{~d} / \mathrm{w}\end{array}$ \\
\hline
\end{tabular}


1998), trials were further stratified according to the duration of $5 \mathrm{FU}$ infusion. Bolus $5 \mathrm{FU}$ were administered in 5 comparisons (Hill et al, 1995; Dufour et al, 1996; Greco et al, 1996; Piga et al, 1996; Palmeri et al, 1998) and continuous infusion 5FU in one comparison (Hill et al, 1995b).

The comparison of $5 \mathrm{FU}+\mathrm{LV}$ versus $5 \mathrm{FU}+\mathrm{LV}+\alpha$-IFN was addressed in 6 trials, the Gruppo Oncologico dell'Italia Meridionale (GOIM) trial (Colucci et al, 1999), the Roma trial (Cassano et al, 1996), the trial from Hungary (Pajkos et al, 1997), the trial from Argentina (Pensel et al, 1993), the Medical Research Council (MRC) trial (Seymour et al, 1996), and the AIO trial (Köhne et al, 1998). The AIO trial (Köhne et al, 1998) and the trial from Hungary (Pajkos et al, 1997) were multiple-arm trials. Two trials (MRC (Seymour et al, 1996), AIO (Köhne et al, 1998)) used a continuous infusion 5FU. Trials were stratified according to $5 \mathrm{FU}$ schedule of administration (5FU bolus and 5FU continuous infusion), and in terms of modulation of $5 \mathrm{FU}$ by leucovorin.

\section{Meta-analysis of 5FU + LV vs. $5 F U+\alpha$-IFN (Table 2)}

The comparison of $5 \mathrm{FU}+\mathrm{LV}$ versus $5 \mathrm{FU}+\alpha$-IFN was addressed in 7 trials, the Corfu-A trial (Corfu-A Study Group, 1995), the GOIRC trial (Di Costanzo et al, 1995), the Yale trial (Marsh et al,), the trial from Turkey (Aykan et al, 1996), the ECOG/CALGB trial (O'Dwyer et al, 1996), the AIO trial (Köhne et al, 1998), the trial Hungary (Pajkos et al, 1997). Three of these trials (O'Dwyer et al, 1996; Pajkos et al, 1997; Köhne et al, 1998) were multiple-arms trials.

In 4 trials same $5 \mathrm{FU}$ schedules were used in the $5 \mathrm{FU} / \mathrm{LV}$ and in the 5FU+IFN arms: 5FU bolus in the GOIRC (Di Costanzo et al, 1995), the Hungary (Pajkos et al, 1997), and the Turkey (Aykan et al, 1996) trials, and 5FU continuous infusion in the AIO (Köhne et al, 1998). In the 3 remaining trials (Corfu-A Study Group, 1995); (Marsh et al) (O’Dwyer et al, 1996) 5FU consisted of bolus injection in the 5FU/LV arm, and of continuous infusion in the 5FU+IFN arm. Trials were therefore stratified according to 5FU administration, i.e. same 5FU schedules in both arms (Di Costanzo et al, 1995; Aykan et al, 1996, Pajkos et al, 1997; Kohne et al, 1998) or 5FU bolus vs. 5FU continuous infusion (Corfu-A Study Group, 1995; (Marsh et al,) (O’Dwyer et al, 1996).

\section{Protocol for the meta-analysis}

In March 1997, all principal investigators received a protocol for the meta-analyses, and were asked to provide individual patient data. Information requested for every randomised patient was date of randomisation, tumour measurability (i.e. measurable or nonmeasurable tumours), treatment assigned by randomisation, age, gender, performance status according to the ECOG scale, primary tumour site (colon or rectum), prior adjuvant chemotherapy, prior chemotherapy for metastatic disease, site of metastases, overall response status with the first assigned treatment, date of response or progression with the first allocated treatment, cross-over to another treatment arm, date of death or last visit, survival status, and cause of death if applicable. Data on toxicity were not collected.

\section{Data collection}

All individual patient data were received by April 1999. Data were extensively checked and discussed with all collaborators present at a plenary meeting of the Meta-Analysis Group In Cancer held in Atlanta, GA, in May 1999.

\section{Tumour response and survival}

Complete response (CR) and partial response (PR) criteria adopted in individual trials followed the World Health Organization recommendations (Miller et al, 1981) and were similar in all trials. Patients experiencing minimal response, stable disease or progressive disease were considered to have no response for the purpose of the meta-analyses. In the MRC trial (Seymour et al, 1996) and in the trial from Hungary (Pajkos et al, 1997) chemotherapy was stopped after 6 months in the absence of tumour progression. In all

Table 2 Randomised clinical trials comparing 5FU + LV to 5FU $+\alpha-I F N$ in advanced colorectal cancer

\begin{tabular}{|c|c|c|}
\hline Comparison & Patients & Treatment arms \\
\hline \multicolumn{3}{|c|}{$5 F U+$ LV vs. $5 F U+\alpha-I F N$, with the same dose of $5 F U$ in both arms } \\
\hline $\begin{array}{l}\text { GOIRC } \\
\text { Di Costanzo et al, } \\
\quad 1995\end{array}$ & 238 & $\begin{array}{l}\text { 5FU } 600 \mathrm{mg} / \mathrm{m}^{2} \text { bolus, + I-folinic acid } 250 \mathrm{mg} / \mathrm{m}^{2} \text { bolus, }+ \text { HU } 3 \mathrm{~g} \text { once a week for } 6 \text { weeks followed by a } 2 \text { week-break } \\
\text { Same without I-folinic acid + I-folinic acid }+\alpha \text {-IFN } 3 \mathrm{MU} \text { three times a week }\end{array}$ \\
\hline $\begin{array}{l}\text { AlO } \\
\text { Köhne et al, } 1998\end{array}$ & 187 & $\begin{array}{l}\text { 5FU } 2600 \mathrm{mg} / \mathrm{m}^{2} \text { continuous infusion }+ \text { LV } 500 \mathrm{mg} / \mathrm{m}^{2} \text { bolus, once a week for } 6 \text { weeks followed by a } 2 \text { week-break } \\
\text { Same without LV }+\alpha \text {-IFN } 3 \mathrm{MU} \text { three times a week }\end{array}$ \\
\hline $\begin{array}{l}\text { Turkey } \\
\text { Aykan et al, } 1996\end{array}$ & 46 & $\begin{array}{l}5 \text { FU } 500 \mathrm{mg} / \mathrm{m}^{2} / \mathrm{d} \text { bolus } \mathrm{d} 1 \text { to } \mathrm{d} 5+\text { I-folinic acid } 100 \mathrm{mg} / \mathrm{m}^{2} \text {, then weekly, every } 4 \text { weeks } \\
\text { Same without I-folinic acid + IFN } 5 \mathrm{MU} \text { three times a week }\end{array}$ \\
\hline Comparison & Patients & Treatment arms \\
\hline \multicolumn{3}{|c|}{$5 F U+$ LV vs. $5 F U+\alpha-I F N$, with a higher dose of $5 F U$ in the $5 F U+\alpha-I F N$ arm } \\
\hline $\begin{array}{l}\text { Corfu-A } \\
\text { Corfu-A Study } \\
\text { Group, } 1995\end{array}$ & 496 & $\begin{array}{l}\text { 5FU } 370 \mathrm{mg} / \mathrm{m}^{2} / \mathrm{d} \text { bolus, + LV } 200 \mathrm{mg} / \mathrm{m}^{2} / \mathrm{d} \text { d1 to d5 every } 4 \text { weeks } \\
5 F U 750 \mathrm{mg} / \mathrm{m}^{2} / \mathrm{d} \text { continuous infusion } \mathrm{d} 1 \text { to } \mathrm{d} 5 \text {, then weekly on bolus }+\alpha \text {-IFN } 9 \mathrm{MU} \text { three times a week }\end{array}$ \\
\hline $\begin{array}{l}\text { ECOG/CALGB } \\
\text { O’Dwyer et al, } 1996\end{array}$ & $6^{443}$ & 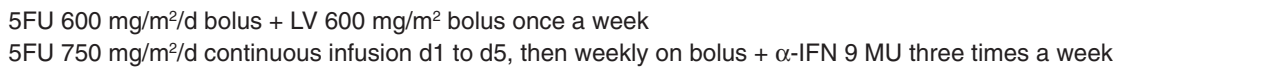 \\
\hline $\begin{array}{l}\text { Hungary } \\
\text { Pajkos et al, } 1997\end{array}$ & 69 & 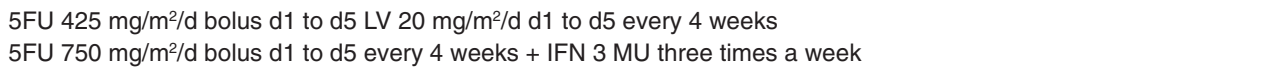 \\
\hline $\begin{array}{l}\text { Yale } \\
\text { Marsh et al }\end{array}$ & 9 & $\begin{array}{l}\text { 5FU } 425 \mathrm{mg} / \mathrm{m}^{2} / \mathrm{d} \text { bolus } \mathrm{d} 1 \text { to } \mathrm{d} 5,+\mathrm{LV} 20 \mathrm{mg} / \mathrm{m}^{2} / \mathrm{d} \text { d } 1 \text { to } \mathrm{d} 5 \text { every } 4 \text { weeks } \\
5 \mathrm{FU} 750 \mathrm{mg} / \mathrm{m} 2 / \mathrm{d} \text { continuous infusion } \mathrm{d} 1 \text { to } \mathrm{d} 5 \text {, then weekly on bolus }+\alpha \text {-IFN } 9 \mathrm{MU} \text { three times a week }\end{array}$ \\
\hline
\end{tabular}


other trials treatment was maintained until disease progression or severe toxicity. Duration of survival was calculated from the date of randomisation to the date of death, whatever its cause.

\section{Statistical methods}

The statistical methods for meta-analyses based on individual patient data have been described in detail in previous publications (ACCMP, 1992; ACCMP, 1994; MAGIC, 1996; MAGIC, 1998a; MAGIC, 1998b). All analyses were based on an intention to treat basis, without any patient exclusion. Tumour responses were compared through relative risks (RR) in individual trials and overall (MAGIC, 1998b). Prognostic factors for response were identified through a logistic regression model (Cox, 1970). Survival times were compared through hazard ratios (HR) in individual trials and overall (Peto et al, 1977). Prognostic factors for survival were identified through a proportional hazards regression model (Cox, 1972). All P values were two-sided.

\section{RESULTS}

\section{Patient characteristics}

A total of 3254 were included in the analyses. The main patient characteristics are listed in Table 3 and 4 . As could be expected in large series of patients, there was no imbalance between the experimental and the control groups for either of the comparisons of interest. $84 \%$ of patients had died at the time of analysis.

\section{Meta-analysis of $5 F U \pm L V$ vs. $5 F U \pm L V+\alpha-I F N$}

1766 patients were included in this meta-analysis. The MRC trial (Seymour et al, 1996), the trial from Argentina (Pensel, 1993), and the trial from Ancona (Piga et al, 1996) allowed the inclusion of patients with non-measurable disease. After exclusion of these patients, 1683 patients were eligible for tumour response assessment. Relative risks for individual trials and overall are presented in Figure 1. Tumour response rates were 18\% (70/387) for patients allocated to $5 \mathrm{FU}$ bolus alone and $21 \%(80 / 376)$ for patients allocated to $5 \mathrm{FU}$ bolus $+\alpha$-IFN $(\mathrm{RR}=0.86 ; 95 \% \mathrm{CI}=0.65-1.15)$. In the only trial using 5FU alone continuous infusion (Hill et al, $1995 \mathrm{~b})$, tumour response rate was $34 \%(27 / 80)$ for $5 \mathrm{FU}$ alone and $22 \%(18 / 80)$ for $5 \mathrm{FU}+\alpha$-IFN $(\mathrm{RR}=1.50 ; 95 \% \mathrm{CI}=0.89-2.5)$.

Tumour response rates were $26 \%(59 / 227)$ for patients allocated to $5 \mathrm{FU}$ bolus $+\mathrm{LV}$ vs. $25 \%(59 / 233)$ for patients allocated to $5 \mathrm{FU}$ bolus + LV $+\alpha$-IFN $(\mathrm{RR}=0.99 ; 95 \% \mathrm{CI}=0.72-1.35)$, and $34 \%$ $(52 / 151)$ for patients allocated to 5FU C.I + LV vs. $30 \%$ for patients allocated to $5 \mathrm{FU}$ C.I. $+\mathrm{LV}+\alpha$-IFN $(\mathrm{RR}=1.14 ; 95 \% \mathrm{CI}=$ 0.81-1.59). The overall tumour response rates were $25 \%$ $(208 / 845)$ for $5 \mathrm{FU} \pm \mathrm{LV}$, and $24 \%(202 / 838)$ for $5 \mathrm{FU} \pm \mathrm{LV}+\alpha-$ IFN $(\mathrm{RR}=1.02 ; 95 \% \mathrm{CI}=0.87-1.2 ; P=0.8)$, showing no advantage for $\alpha$-IFN administration.

There was no statistically significant survival difference between $5 \mathrm{FU}$ and $5 \mathrm{FU}+\alpha$-IFN, nor between $5 \mathrm{FU}+\mathrm{LV}$ and $5 \mathrm{FU}$ $+\mathrm{LV}+\alpha$-IFN (Figure 2). The overall survival hazard ratio for the meta-analysis of $5 \mathrm{FU} \pm \mathrm{LV}$ versus $5 \mathrm{FU} \pm \mathrm{LV}+\alpha$-IFN was 0.95 $(95 \% \mathrm{CI}=0.86-1.05 ; P=0.33)$, showing no advantage for $\alpha$-IFN

Table 3 Patient characteristics: 5FU+/-LV vs. 5FU+/-LV+IFN

\begin{tabular}{|c|c|c|c|c|c|c|c|c|}
\hline \multirow[t]{2}{*}{ Trial } & \multirow{2}{*}{$\begin{array}{c}\text { Accrual } \\
\text { period }\end{array}$} & \multirow[t]{2}{*}{ Trt. } & \multirow{2}{*}{$\begin{array}{c}\text { No. of } \\
\text { patients }\end{array}$} & \multirow{2}{*}{$\begin{array}{c}\text { Adjuvant } \\
\text { chemo. (\%) }\end{array}$} & \multirow{2}{*}{$\begin{array}{l}\text { Primary } \\
\text { colon (\%) }\end{array}$} & \multirow{2}{*}{$\begin{array}{c}P S<2 \\
(\%)\end{array}$} & \multicolumn{2}{|c|}{ Metastases (\%) } \\
\hline & & & & & & & Liver only & Lung only \\
\hline RICRC & 1989-92 & $5 F U$ & 124 & 0 & NA & 83 & 62 & 9 \\
\hline \multicolumn{2}{|c|}{ Greco et al, 1996} & $5 F U+I F N$ & 121 & 0 & NA & 92 & 63 & 4 \\
\hline Palermo & 1990-93 & $5 F U$ & 88 & 0 & 100 & 95 & 62 & 3 \\
\hline \multicolumn{2}{|c|}{ Palmeri et al, 1998} & $5 F U+I F N$ & 81 & 0 & 100 & 97 & 61 & 0 \\
\hline Ancona & 1990-93 & $5 F U$ & 72 & 3 & 75 & 97 & 44 & 6 \\
\hline \multicolumn{2}{|c|}{ Piga et al, 1996} & $5 F U+I F N$ & 69 & 3 & 72 & 97 & 45 & 6 \\
\hline $\mathrm{RMH}$ & 1990-92 & $5 \mathrm{FU}$ & 54 & 0 & 63 & 87 & 28 & 2 \\
\hline \multicolumn{2}{|c|}{ Hill et al, 1995a } & $5 \mathrm{FU}+\mathrm{IFN}$ & 52 & 0 & 71 & 77 & 19 & 13 \\
\hline France & 1990-93 & $5 \mathrm{FU}$ & 50 & 0 & 73 & 100 & 52 & 6 \\
\hline \multicolumn{2}{|c|}{ Dufour et al, 1996} & $5 F U+I F N$ & 56 & 0 & 73 & 100 & 48 & 11 \\
\hline RMH PVI & $1992-94$ & $5 F U$ & 80 & 0 & 81 & 58 & 19 & 9 \\
\hline \multicolumn{2}{|c|}{ Hill et al, 1995b } & $5 F U+I F N$ & 80 & 0 & 70 & 60 & 19 & 9 \\
\hline GOIM & $1991-94$ & $5 F U / L V$ & 101 & 0 & 56 & 88 & 41 & 7 \\
\hline \multicolumn{2}{|c|}{ Colucci et al, 1999} & $5 F U / L V+I F N$ & 103 & 1 & 66 & 95 & 40 & 2 \\
\hline Roma & 1990-96 & $5 \mathrm{FU} / \mathrm{LV}$ & 73 & 0 & 67 & 79 & 17 & 3 \\
\hline \multicolumn{2}{|c|}{ Cassano et al, 1996} & $5 F U / L V+I F N$ & 75 & 0 & 71 & 81 & 10 & 3 \\
\hline Hungary & $1993-96$ & $5 F U / L V$ & 35 & 0 & 47 & 74 & 60 & 0 \\
\hline \multicolumn{2}{|c|}{ Pajkos et al, 1997} & $5 F U / L V+I F N$ & 38 & 0 & 66 & 76 & 39 & 3 \\
\hline Argentina & $1990-91$ & $5 \mathrm{FU} / \mathrm{LV}$ & 28 & 0 & 61 & 57 & 43 & 0 \\
\hline \multicolumn{2}{|c|}{ Pensel et al, 1993} & $5 F U / L V+I F N$ & 27 & 0 & 59 & 59 & 41 & 7 \\
\hline MRC & $1991-93$ & $5 F U / L V$ & 132 & 1 & 69 & 74 & 43 & 3 \\
\hline \multicolumn{2}{|c|}{ Seymour et al, 1996} & $5 F U / L V+I F N$ & 128 & 1 & 67 & 76 & 36 & 5 \\
\hline $\mathrm{AlO}$ & $1992-93$ & $5 \mathrm{FU} / \mathrm{LV}$ & 50 & 10 & 46 & 94 & 34 & 0 \\
\hline \multicolumn{2}{|c|}{ Köhne et al, 1998} & $5 F U / L V+I F N$ & 49 & 6 & 51 & 96 & 44 & 4 \\
\hline \multirow[t]{2}{*}{ Total } & 1989-96 & $5 \mathrm{FU}+/-\mathrm{LV}$ & 887 & 1 & 70 & 98 & 43 & 5 \\
\hline & & $5 F U+/-L V+I F N$ & 879 & 1 & 71 & 98 & 40 & 5 \\
\hline
\end{tabular}

$\mathrm{NA}=$ not available. 
Table 4 Patient characteristics: 5FU+LV vs. 5FU+IFN

\begin{tabular}{|c|c|c|c|c|c|c|c|c|}
\hline \multirow[t]{2}{*}{ Trial } & \multirow{2}{*}{$\begin{array}{l}\text { Accrual } \\
\text { Period }\end{array}$} & \multirow[t]{2}{*}{ Trt. } & \multirow{2}{*}{$\begin{array}{c}\text { No.of } \\
\text { Patients }\end{array}$} & \multirow{2}{*}{$\begin{array}{c}\text { Adjuvant } \\
\text { Chemo. (\%) }\end{array}$} & \multirow{2}{*}{$\begin{array}{l}\text { Primary } \\
\text { colon (\%) }\end{array}$} & \multirow{2}{*}{$\begin{array}{c}P S<2 \\
(\%)\end{array}$} & \multicolumn{2}{|c|}{ Metastases (\%) } \\
\hline & & & & & & & Liver only & Lung only \\
\hline Corfu-A & 1989-91 & 5FU/LV & 250 & 0 & NA & 83 & 38 & 4 \\
\hline \multicolumn{2}{|c|}{ Corfu-A Study Group, 1995} & $5 F U+I F N$ & 246 & 0 & NA & 83 & 37 & 4 \\
\hline ECOG & 1990-95 & $5 F U / L V$ & 224 & 12 & 68 & 92 & 37 & 11 \\
\hline \multicolumn{2}{|c|}{ O’Dwyer et al, 1996} & $5 F U+I F N$ & 219 & 11 & 73 & 95 & 35 & 9 \\
\hline $\mathrm{AlO}$ & 1992-95 & 5FU/LV & 93 & 12 & 50 & 96 & 44 & 4 \\
\hline \multicolumn{2}{|c|}{ Köhne et al, 1998} & $5 F U+I F N$ & 94 & 11 & 61 & 92 & 39 & 7 \\
\hline GOIRC & 1992-94 & 5FU/LV & 119 & 0 & 64 & 98 & 56 & 4 \\
\hline \multicolumn{2}{|c|}{ Di Costanzo et al, 1995} & $5 F U+I F N$ & 119 & 0 & 59 & 97 & 59 & 5 \\
\hline Hungary & 1993-96 & 5FU/LV & 35 & 0 & 47 & 74 & 60 & 0 \\
\hline \multicolumn{2}{|c|}{ Pajkos et al, 1998} & $5 F U+I F N$ & 34 & 0 & 53 & 79 & 50 & 3 \\
\hline Turkey & 1992-94 & 5FU/LV & 19 & 15 & 50 & 72 & 21 & 0 \\
\hline \multicolumn{2}{|c|}{ Aykan et al, 1996} & $5 F U+I F N$ & 27 & 15 & 21 & 62 & 37 & 11 \\
\hline Yale & 1990-91 & 5FU/LV & 4 & 0 & 75 & 100 & 25 & 25 \\
\hline \multicolumn{2}{|c|}{ Marsh et al } & $5 F U+I F N$ & 5 & 0 & 100 & 80 & 60 & 0 \\
\hline \multirow[t]{2}{*}{ Total } & 1989-96 & 5FU/LV & 744 & 6 & 61 & 89 & 42 & 6 \\
\hline & & $5 F U+I F N$ & 744 & 5 & 64 & 89 & 41 & 6 \\
\hline
\end{tabular}

$\mathrm{NA}=$ not available.

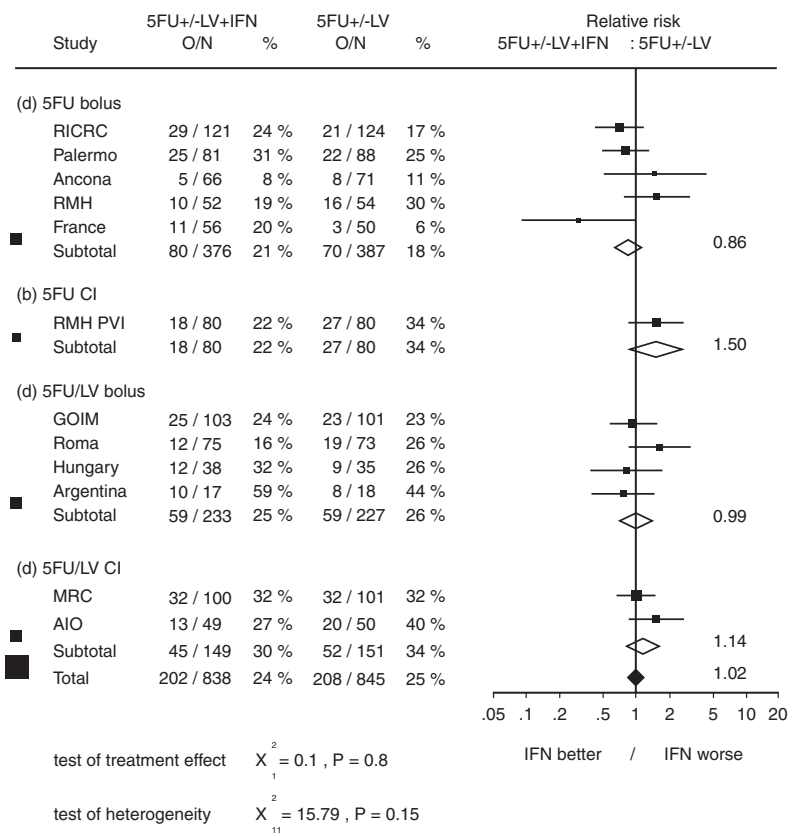

Figure 1 Tumour response relative risks in individual trials and overall for the meta-analysis $5 \mathrm{FU} \pm \mathrm{LV}$ vs. $5 \mathrm{FU} \pm \mathrm{LV}+\alpha-\mathrm{IFN}$

administration. Median survivals were 11.4 months for patients treated without $\alpha$-IFN, and 11.5 months for patients treated with $\alpha$-IFN.

\section{Meta-analysis of $5 \mathrm{FU}+\mathrm{LV}$ vs. $5 \mathrm{FU}+\alpha-\mathrm{IFN}$}

1488 patients were included in this meta-analysis.

The ECOG/CALGB trial (O'Dwyer et al 1996) allowed the inclusion of patients with non-measurable disease. After exclusion of these patients, 1305 patients were eligible for tumour response assessment.
Tumour response rates were $23 \%(152 / 655)$ for patients allocated to $5 \mathrm{FU}+\mathrm{LV}$ vs. $18 \%$ (115/650) for patients allocated to $5 \mathrm{FU}$ $+\alpha$-IFN. The overall tumour response RR was $1.26(95 \% \mathrm{CI}=$ $1.01-1.59 ; P=0.042)$, showing a statistically significant advantage for $5 \mathrm{FU}+\mathrm{LV}$ over $5 \mathrm{FU}+\alpha$-IFN (Figure 3). However, the heterogeneity between trials in this meta-analysis was rather important ( $P$ value for heterogeneity, $P=0.001$ ), mostly between trials using the same 5FU schedules in both treatment arms ( $P$ value for heterogeneity, $P=0.003$ ).

Analyses stratified by type of 5FU administration showed that the advantage of $5 \mathrm{FU}+\mathrm{LV}$ over $5 \mathrm{FU}+\alpha$-IFN was limited to the group of trials using the same 5FU schedules in both treatment arms $(\mathrm{RR}=1.80 ; 95 \% \mathrm{CI}=1.29-2.51 ; P=0.0005)$.

Survival analysis showed a small trend in favour of $5 \mathrm{FU}+\mathrm{LV}$ over $5 \mathrm{FU}+\alpha$-IFN, but this advantage was not statistically significant (overall HR $=1.11 ; 95 \% \mathrm{CI}=0.99-1.24 ; P=0.066$ ) (Figure 4). Median survivals were 11.7 months for patients allocated to $5 \mathrm{FU}+\mathrm{LV}$ and 11.3 months for patients allocated to $5 \mathrm{FU}+$ $\alpha$-IFN. The survival difference reached statistical significance in the group of trials using the same $5 \mathrm{FU}$ schedules in both treatment arms $(\mathrm{HR}=1.29 ; 95 \%$ CI $1.07-1.57 ; P=0.008)$. There was some heterogeneity in this group of trials, but which did not reach a statistically significant level $(P=0.67)$.

\section{Prognostic factor analyses}

Individual patient data used for the two meta-analyses were combined to identify prognostic factors for response and survival (3254 patients). Sex, age, performance status (PS), primary tumour site, previous adjuvant chemotherapy, metastatic site, and allocated treatment (no $\alpha$-IFN vs. $\alpha$-IFN) were considered in these analyses. In a logistic regression model, metastases confined to the liver $\left(P<10^{-4}\right)$, and primary rectal tumours $(P=0.042)$ were the independent favourable prognostic factors for tumour response. Tumour response rates were $26 \%$ for patients with metastases confined to the liver versus $20 \%$ for the others. Patients with rectal cancer had a $26 \%$ tumour response rate, vs. $22 \%$ with colon tumour. 


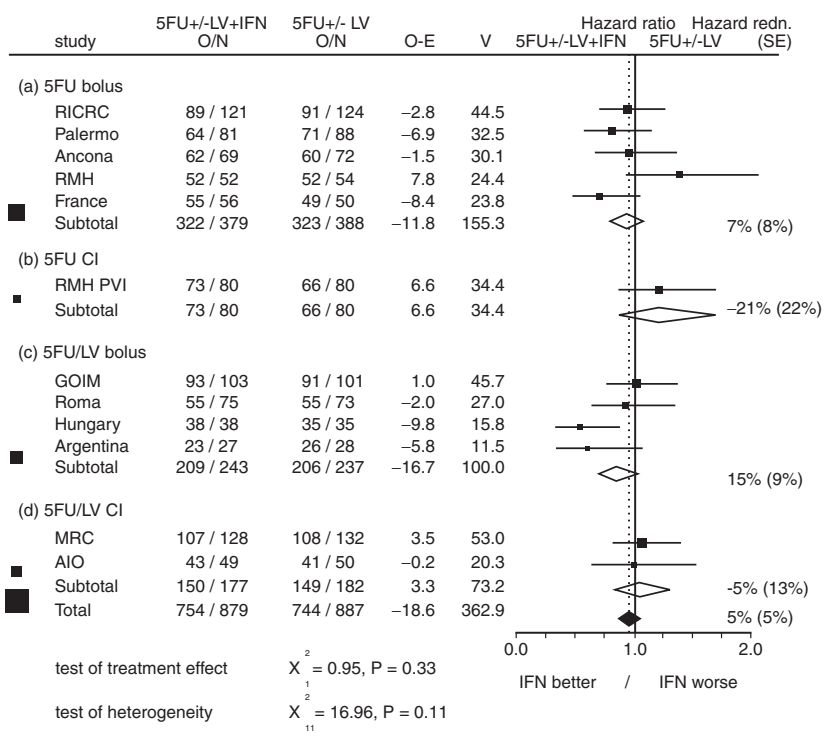

Figure 2 Survival hazard ratios in individual trials and overall for the meta-analysis $5 \mathrm{FU} \pm \mathrm{LV}$ vs. $5 \mathrm{FU} \pm \mathrm{LV}+\alpha-\mathrm{IFN}$

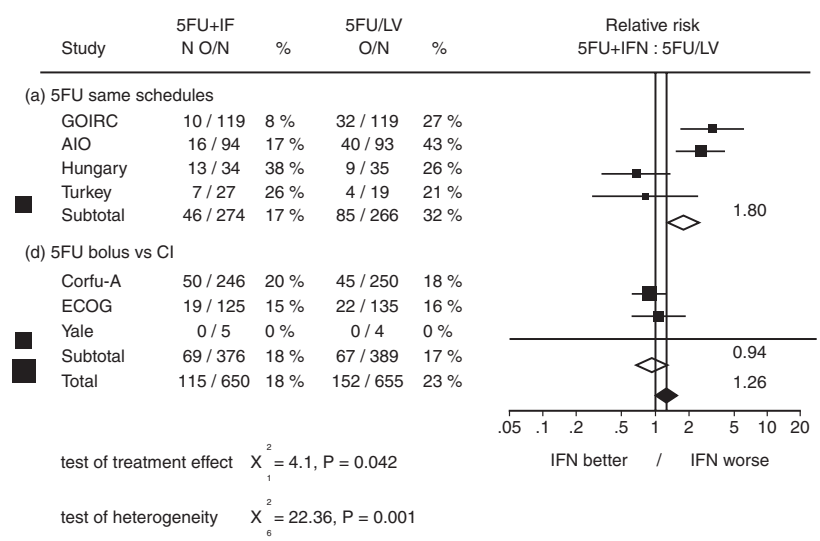

Figure 3 Tumour response relative risks in individual trials and overall for the meta-analysis $5 \mathrm{FU}+\mathrm{LV}$ vs. $5 \mathrm{FU}+\alpha-\mathrm{IFN}$

In a Cox regression model, good PS $\left(P<10^{-4}\right)$, metastases confined to the liver or confined to the lung $(P=0.0002$ and $P=$ 0.004 respectively), and primary tumour in the rectum $(P=0.003)$ were the independent favourable prognostic factors for survival. One-year survival was $59 \%$ for patients with PS $0,47 \%$ for patients with PS 1, and 30\% for patients with PS 2 or worse; $54 \%$ for patients with metastases confined to the liver, $46 \%$ for the others; $61 \%$ for patients with metastases confined to the lung, $49 \%$ for the others; $56 \%$ for patients with primary rectal cancer, $47 \%$ for the others.

\section{DISCUSSION}

Pre-clinical studies indicate that $\alpha$-IFN may increase the cytotoxicity of 5FU in a variety of tumour cell lines (Elias and Crissman, 1988; Wadler et al, 1990). Several mechanisms of interaction between $5 \mathrm{FU}$ and interferon have been demonstrated. In vitro data published by Elias and Crissman (Elias and Crissman, 1988) suggest that the enzyme thymidylate synthase might be a target for this interaction. Moreover, the presence of thymidine in the culture

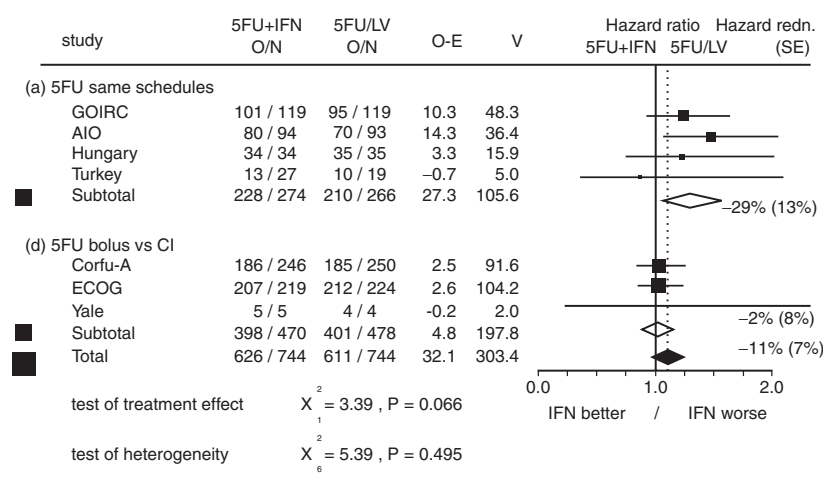

Figure 4 Survival hazard ratios in individual trials and overall for the meta-analysis $5 \mathrm{FU}+\mathrm{LV}$ vs. $5 \mathrm{FU}+\alpha$-IFN

medium tends to block the synergic effect (Neefe and John, 1991). Interferon may also modify the plasma pharmacokinetics of 5FU (Lindley et al, 1990; Danhouser et al, 1991). Finally, 5FU may influence the immunomodulatory actions of interferon (Neefe and John, 1991). However, despite more than 3000 patients included in randomized trials, the clinical impact of combining $\alpha$-IFN to $5 \mathrm{FU}$ remained debatable.

The 2 meta-analyses presented here address the efficacy of $\alpha$-IFN combined with 5FU in advanced colorectal cancer. Tumour response rate and survival were the two main end points. Toxicity was not studied, since at the time of beginning these meta-analyses individual trials had already demonstrated that the addition of $\alpha$-IFN to a $5 F U$ regimen led to an increased risk of neutropenia, mucositis, and neurotoxicity, and was associated with flu-like syndromes. $\alpha$-IFN also produced a significant impairment of quality of life in the MRC trial (Seymour et al, 1996).

The meta-analysis of trials comparing $5 \mathrm{FU} \pm \mathrm{LV}$ to a similar 5 FU regimen plus $\alpha$-IFN failed to show any difference between control and experimental arms in terms of tumour response or survival. The tumour response rate with $5 \mathrm{FU}$ bolus alone reported in the group of trials comparing $5 \mathrm{FU}$ to $5 \mathrm{FU}+\alpha$-IFN was rather high $(19 \%)$, compared to tumour responses reported for patients receiving 5FU bolus in the 4 meta-analyses previously performed by our group, which varied between $11 \%$ and 14\% (ACCMP, 1992, 1994; MAGIC, 1996, 1998a). This may reflect a selection of patients with favourable prognostic characteristics in trials included in the present meta-analysis, but does not invalidate our finding of no difference between $5 \mathrm{FU}$ alone and $5 \mathrm{FU}+\alpha$-IFN. It should also be noted that the doses of 5FU delivered in the 5FU alone arms were generally high compared with the 5FU doses reported in our previous meta-analyses.

In contrast, the meta-analysis of trials comparing $5 \mathrm{FU}+\mathrm{LV}$ to 5 FU $+\alpha$-IFN showed higher response rates and a trend towards longer survival in favour of $5 \mathrm{FU}+\mathrm{LV}$. In this set of trials, the overall tumour response rate and the median survival of patients receiving $5 \mathrm{FU}+\mathrm{LV}$ (23\% and 13 months, respectively) were remarkably similar to those reported previously in the metaanalysis of trials comparing 5FU to 5FU + LV (ACCMP, 1992), ( $23 \%$ and 11.5 months, respectively). Thus, the advantage of 5FU + LV over $5 \mathrm{FU}+\alpha$-IFN observed in the present meta-analysis does not seem to be due to some selection bias that might have favoured patients allocated to the $5 \mathrm{FU}+\mathrm{LV}$ arm.

In this meta-analysis, the stratification of trials by type of $5 \mathrm{FU}$ administration (Figures 3 and 4) showed a statistically significant 
advantage of $5 \mathrm{FU} / \mathrm{LV}$ over $5 \mathrm{FU}+\mathrm{IFN}$ in the group of trials using the same 5FU schedules in both arms. By contrast, there was no difference between the two treatment arms when 5FU was administered by bolus in the $5 \mathrm{FU} / \mathrm{LV}$ arm and by continuous infusion in the $5 \mathrm{FU}+$ IFN. This could be linked to the tumour response and survival advantage of $5 \mathrm{FU}$ continuous infusion over $5 \mathrm{FU}$ bolus demonstrated in one of our previous meta-analyses (MAGIC, 1998a).

$5 \mathrm{FU}$ dose intensity is not a valid parameter when comparing bolus versus infusion or mixed regimens. Consequently, no attempt was made to stratify trials according to 5FU dose intensity.

The prognostic factor analysis confirms well-established results, such as the key role of performance status for survival. Other findings are less classical, such as the role of primary and metastatic tumour sites, and are currently under investigation by our group, on the basis of 7000 individual patient data with advanced colorectal cancer. In the adjuvant setting, a trial conducted by the National Surgical Adjuvant Breast and Bowel Project (NSABPC05) also failed to show any advantage for $5 \mathrm{FU}+\mathrm{LV}+\alpha$-IFN over 5FU + LV in patients with stage II-III colon cancer (Wolmark et al, 1998). On-going studies are currently addressing the interest of other types of interferon, such as $\alpha-2 \mathrm{c}$ IFN and $\beta$-IFN (Villar Grimalt et al, 1999). However, new agents, such as CPT-11 (irinotecan) (Douillard et al, 2000; Saltz et al, 2000) or oxaliplatin (de Gramont et al, 2000) have demonstrated clinical benefits in advanced colorectal cancer, and are therefore more plausible candidates for the adjuvant setting.

We conclude that $\alpha$-IFN does not increase the efficacy of 5FU in advanced colorectal cancer, and should not be offered in routine clinical practice.

\section{ACKNOWLEDGMENTS}

This study was supported in part by the European Association for Research in Oncology (A.E.R.O.), France, and by Roche Laboratories. The authors thank Youri Piedbois for data management and statistical support.

\section{REFERENCES}

Advanced Colorectal Cancer Meta-analysis Project (1992) Modulation of 5fluorouracil by leucovorin in patients with advanced colorectal cancer: evidence in terms of response rate. J Clin Oncol 10: 896-903

Advanced Colorectal Cancer Meta-analysis Project (1994) Meta-analysis of randomized trials testing the biochemical modulation of 5-fluorouracil by methotrexate in metastatic colorectal cancer. J Clin Oncol 12: 960-969

Aykan NF, Uskent N, Yaylaci M, et al (1996) 5-fluorouracil plus interferon alpha-2b versus 5-fluorouracil plus folinic acid in advanced colorectal cancer; same efficacy but different toxicity. Ann Oncol 7 (suppl 5): 42 (abstract 195)

Cassano A, Pozzo C, Corsi DC, et al (1996) The role of interferon alpha-2b in the treatment with folinic acid and 5-fluorouracil of advanced colorectal cancer: a randomized study. 9th NCI-EORTC symposium on new drugs in cancer therapy; March 12-15, 1996, Amsterdam. Ann Oncol 7 (Suppl 1): 69 (abstract 234)

Colucci G, Maiello E, Gebbia V et al (1999) 5-Fluorouracil and Levofolinic acid with or without recombinant interferon- $2 \mathrm{~b}$ in patients with advanced colorectal carcinoma. A randomized multicenter study with stratification for tumor burden and liver involvement by the Southern Italy Oncology Group. Cancer 85: $535-545$

Corfu-A Study Group (1995) Phase III randomized study of two fluorouracil combinations with either interferon alpha-2a or leucovorin for advanced colorectal cancer. J Clin Oncol 13: 921-928

Cox DR (1970) The analysis of binary data. London, United Kingdom, Methuen.

Cox DR (1972) Regression models and life tables (with discussion). JR Stat Soc B 34: $187-220$
Danhauser L, Gilchrist T, Friemann J et al. (1991) Effect of recombinant interferonalpha-2b on the plasma pharmacokinetics of fluorouracil in patients with advanced cancer. Proc Am Assoc Cancer Res 32: 1052 (abstr)

de Gramont A, Figer A, Seymour M, Homerin M, Hmissi A, Cassidy J, Boni C, Cortes-Funes H, Cervantes A, Freyer G, Papamichael D, Le Bail N, Louvet C, Hendler D, de Braud F, Wilson C, Morvan F and Bonetti A (2000) Leucovorin and fluorouracil with or without oxaliplatin as first-line treatment in advanced colorectal cancer. J Clin Oncol 18: 2938-2947

Di Costanzo F, El-Taani H, Marzola M, et al (1995) Hydroxyurea (HU), high dose folinic acid (1-FA) and 5FU vs HU, 5FU and interferon-alfa-2b (IFN) in advanced colorectal cancer (ACRC): a randomized trial of the Italian Oncology Group for Clinical Research (GOIRC). Proc Am Soc Clin Oncol 14: 208 (abstract 508)

Douillard JY, Cunningham D, Roth AD, Navarro M, James RD, Karasek P, Jandik P, Iveson T, Carmichael J, Alakl M, Gruia G, Awad L and Rougier P (2000). Irinotecan combined with fluorouracil compared with fluorouracil alone as first-line treatment for metastatic colorectal cancer: a multicentre randomised trial. Lancet 355: 1041-1047

Dufour P, Husseini F, Dreyfus B et al (1996) 5-Fluorouracil versus 5-Fluorouracil plus alpha-interferon as treatment of metastatic colorectal carcinoma. A randomized study. Ann Oncol 7: 575-579.

Elias L and Crissman HA (1988) Interferon effects upon the adenocarcinoma 38 and HL-60 cell lines: antiproliferative responses and synergistic interactions with halogenated pyrimidine antimetabolites Cancer Res $\mathbf{4 8}$ 4868-4873

Greco FA, Figlin R, York M et al (1996) Phase III randomized study to compare interferon alpha-2a in combination with fluorouracil versus fluorouracil alone in patients with advanced colorectal cancer. J Clin Oncol 14: 2674-2681

Hill M, Norman A, Cunningham D et al (1995a): Royal Marsden phase III trial of fluorouracil with or without interferon Alfa-2b in advanced colorectal cancer. J Clin Oncol 13: 1297-1302

Hill M, Norman A, Cunningham D et al (1995b) Impact of protracted venous infusion fluorouracil with or without interferon alpha- $2 \mathrm{~b}$ on tumor response, survival, and quality of life in advanced colorectal cancer. J Clin Oncol 13: $2317-2323$

Köhne CH, Schöffski P, Wilke H et al (1998) Effective biomodulation by leucovorin or high-dose infusion fluorouracil given has a weekly 24-hour infusion: results of a randomized trial in patients with advanced colorectal cancer. J Clin Oncol 16: $418-426$

Kosmidis PA, Tsavaris N, Skarlos D et al (1996) Fluorouracil and leucovorin with or without interferon alfa- $2 \mathrm{~b}$ in advanced colorectal cancer: analysis of a prospective randomized phase III trial. Hellenic Cooperative Oncology Group. $J$ Clin Oncol 14: 2682-2687

Kreuser ED, Streit M, Kuchler T et al (1995) A multicenter randomized trial with the assessment of quality of life in patients with metastatic colorectal carcinoma given either folinic acid or interferon $\alpha-2 b$ as a modulator of 5-fluorouracil. $\operatorname{PrC}$ Am Soc Clin Oncol 14: 202 (abstract 485)

Lindley C, Bernard B, Gavlan M et al (1990) Interferon-alpha increases 5fluorouracil levels 16-fold within 1 hour: results of a phase I study. J Interferon Res 10: 9-15

Marsh JC and Rosenberg AH, YALE-HIC-5698, NCI-V91-0053. Phase III comparison of 5FU/low-dose CF vs 5FU/IFN-A in patients with metastatic or recurrent colorectal adenocarcinoma. PDQ Notice

Meta-Analysis Group In Cancer (1996) Reappraisal of hepatic arterial infusion in the treatment of non resectable liver metastases from colorectal cancer. $J$ Natl Cancer Inst 88: 252-258

Meta-Analysis Group In Cancer (1998a) Efficacy of intravenous continuous infusion of fluorouracil compared with bolus administration in advanced colorectal cancer. J Clin Oncol 16: 301-308

Meta-Analysis Group In Cancer (1998b) Toxicity of fluorouracil in patients with advanced colorectal cancer: effect of administration schedule and prognostic factors. J Clin Oncol 16: 3537-3541

Miller AB, Hoogstraten B, Staquet M and Winkler A (1981) Reporting results of cancer treatment. Cancer 47: 207-214

Neefe JR and John W (1991) Mechanisms of interaction of interferon and 5 fluorouracil in solid tumors. Semin Oncol 18 (suppl 7): 77-82

O'Dwyer PJ, Ryan LM, Valone FH et al (1996) Phase III of biochemical modulation of 5-fluorouracil by IV or oral leucovorin or by interferon in advanced colorectal cancer: an ECOG/CALGB phase III trial. Proc Am Soc Clin Oncol 15: 207 (abstract 469).

Pajkos G, Izso J, Kristo K et al (1997) Biochemical modulation of 5-fluorouracil (FU) by leucovorin (LV) and/or interferon alpha-2a (IFN) in metastatic colorectal cancer (MCC). Anti-Cancer Treatment, Seventh International Congress 1997, Paris, February 6-9, 1997: 194 (abstract 275) 
Palmeri S, Danova M, Bernardo G et al (1998) 5-Fluorouracil plus interferon alpha2a compared to 5-Fluorouracil alone in the treatment of advanced colon carcinoma: a multicentric randomized study. J Cancer Res Clin Oncol 124: 191-198

Pazdur R, Ajani JA, Patt YT et al (1990) Phase II study of fluorouracil and recombinant interferon alpha-2a in previously untreated advanced colorectal carcinoma. J Clin Oncol 10: 2027-2031

Pensel R (1993). Advanced colon cancer (ACC): a randomized trial of fluorouracil (5FU)+folinic acid (FA) and 5FU+FA+Interferon alpha-2b (IFN). Proc Am Soc Clin Oncol 12: 203 (abstract 602)

Peto R, Pike MC, Armitage P et al (1977) Design and analysis of randomized clinical trials requiring prolonged observation of each patient (II. Analysis and examples). Br J Cancer 35:1-39

Piedbois P, Gimonet JF, Feuilhade F et al (1991) 5FU, folinic acid and alpha-2ainterferon combination in advanced gastrointestinal cancer. Proceedings of the American Society of Clinical Oncology 10: 430

Piga A, Cascinu S, Latini L et al (1996) A phase II randomised trial of 5-fluorouracil with or without interferon alpha-2a in advanced colorectal cancer. B J Cancer 74: 971-974

Raderer M and Scheithauer W (1995) Treatment of advanced colorectal cancer with 5-fluorouracil and interferon-alpha: an overview of clinical trials. Eur J Cancer 31A: $1002-1008$

Recchia F, Nuzzo A, Lalli A et al (1996) Randomized trial of 5-fluorouracil and high dose folinic acid with or without alpha- $2 \mathrm{~b}$ interferon in advanced colorectal cancer. Am J Clin Oncol 19: 301-304
Saltz LB, Cox JV, Blanke C, Rosen LS, Fehrenbacher L, Moore MJ, Maroun JA, Ackland SP, Locker PK, Pirotta N, Elfring GL and Miller LL (2000) Irinotecan plus fluorouracil and leucovorin for metastatic colorectal cancer. Irinotecan Study Group. $N$ Engl J Med 343: 905-914

Seymour MT, Slevin ML, Kerr DJ et al (1996) Randomized trial assessing the addition of interferon alpha-2a to fluorouracil and leucovorin in advanced colorectal cancer. J Clin Oncol 14: 2280-2288

Villar-Grimalt A, Candel MT, Massuti B et al (1999) A randomized phase II trial of 5-fluorouracil, with or without human interferon-beta, for advanced colorectal cancer. Br J Cancer 80(5-6): 786-791

Wadler S, Schwartz EL, Goldman M et al (1989) Fluorouracil and recombinant alpha-2a-interferon: an active regimen against advanced colorectal carcinoma. J Clin Oncol 12: 1769-1775

Wadler S, Wersto R, Weinberg V et al (1990) Interaction of fluorouracil and interferon in human colon cancer cell lines: cytotoxic and cytokinetic effects. Cancer Res 50: 2653-2665

Weh HJ, Platz D, Braumann D et al (1992) Treatment of metastatic colorectal carcinoma with a combination of fluorouracil and recombinant interferon alpha-2b: preliminary-data of a phase II study. Semin Oncol Suppl 2: $180-184$

Wolmark N, Bryant J, Smith R et al (1998) Adjuvant 5-fluorouracil and leucovorin with or without interferon alfa-2a in colon carcinoma: National Surgical Adjuvant Breast and Bowel Project protocol C-05. J Natl Cancer Inst 90(23): 1810-1816 
Pierre Thirion, MD

Department of Radiotherapy

Saint Luke's Hospital

Highfield Road

Rathgar

DUBLIN 6

IRELAND

Pascal Piedbois, MD, PhD

Department of Medical Oncology

Hôpital Henri Mondor

Assistance Publique - Hôpitaux de Paris

51 avenue du Maréchal de Lattre de

Tassigny

F-94010 CRÉTEIL CEDEX

FRANCE

Marc Buyse, ScD

International Drug

Development Institute

430 avenue Louise, B14

B-1050 BRUSSELS

BELGIUM

Peter J. O'Dwyer, MD

Fox Chase Cancer Center

Section of Urology

1500 E Medical Center Dr.

Ann Arbor, MI 48109-0330

USA

David Cunningham, MD

Cancer Research Campaign, Section of Medicine

The Royal Marsden Hospital

Downs Road

SUTTON

Surrey

SM2 5PT

UNITED KINGDOM

Anthony Man, MD

Department of Clinical Pharmacology and Clinical Research Novartis Pharma

CH-4002 BASEL

SWITZERLAND

Frank A. Greco, MD

Sarah Cannon Cancer Center

250 25th Avenue North

Suite 412

NASHVILLE, TN 37203-1632

USA

Giuseppe Colucci, MD

Department of Medicine

Oncology Institute

Via Amendola, 209

\section{I-70126 BARI}

ITALY

Claus-Henning Köhne, MD

Abt. für Hämatologie, Onkologie and Tumorimmunologie

Virchow-Klinikum

Robert-Rössle-Klinik

Linderberger Weg 80

D-13122 BERLIN

GERMANY

Francesco Di Costanzo, MD

Servicio Oncoligico

Azienda Ospedaliera "S. Maria"

Via T. di Joannuccio

I-05100 TERNI

ITALY

Andrea Piga, MD

Medical Oncology

University of Ancona

Ospedale Torrette

I-60020 ANCONA

ITALY

Sergio Palmeri, MD

Ass. Professor of Medical Oncology

Istituto di Clinica Medica, University of Palermo

Policlinico "P. Giaccone”, p.zza delle

Cliniche, 2

I-90127 PALERMO

ITALY

Patrick Dufour, MD

Département OncoHématologie

CHU Hautepierre

Avenue Molière

F-67098 STRASBOURG CEDEX

FRANCE

Alessandra Cassano, MD PhD

Department of Internal Medicine/Medical

Oncology

Universita Catolica S. Cuore

Largo A. Gemelli 8

I-00168 ROMA

ITALY

Gábor Pajkos, M.D.

MI Central Hospital

2nd Dept. Internal Medicine-Oncology

BUDAPEST

1406 P.O.B. 23

HUNGARY

Raul Augusto Pensel, MD

Centro Oncologico "Dr Alejandro Catarineu" 
Carlos Calvo 1777

1102 Buenos Aires

ARGENTINA

N. Faruk Aykan, MD

Istanbul University

Institute of Oncology

34390 ÇAPA, ISTANBUL

TURKEY

John Marsh, MD

Yale Comprehensive Cancer Center
P.O. Box 208032

333 Cedar Street

NEW HAVEN, CT 06520-8032

USA

Matthew T. Seymour

University of Leeds

Cookridge Hospital

Regional Centre for Cancer Treatment

LEEDS

LS16 6QB

UNITED KINGDOM 